\title{
Unequal opportunities and human capital formation
}

\author{
Daniel Mejía ${ }^{1}$ \\ Brown University, and \\ Banco de la República, Colombia. \\ Marc St-Pierre \\ Brown University.
}

April, 2004

Preliminary draft

\begin{abstract}
This paper develops a tractable, heterogeneous agents general equilibrium model where agents face different costs of access to the educational system. The paper explores the relation between inequality of opportunities (in the form of differential costs of access to the educational process) and efficiency (the levels of human capital and output) . More precisely, the results from the simulation of the model suggest that a higher level of inequality of opportunities is associated with a lower level of average human capital, lower output per worker and higher income (wage) inequality. In other words, the model (based on standard assumptions) does not predict a trade-off between efficiency and equal opportunity in human capital formation.
\end{abstract}

Keywords: Human Capital, Inequality, Equity-Efficiency Tradeoff.

JEL Classification Numbers: J24, J31, O15, D33.

\footnotetext{
${ }^{1}$ Corresponding author. Address: Department of Economics, Brown University, Box B, Providence, RI 02912. E-mail: Daniel_Mejia@brown.edu. We are grateful to Pedro Dal Bó, Oded Galor, Peter Howitt, Tom Krebs, Herakles Polemarchakis and participants at the Macro Lunch at Brown University for many helpful suggestions. All remaining errors are our responsability.
} 


\section{Introduction}

Most of the literature that studies the effects of income inequality on economic growth through its effects on human capital has focused on the role of credit constraints. The main idea of this line of research is the following: relatively poor agents don't have the means to finance the accumulation of human capital and, because they are credit constrained (that is, there is no way to finance the costs of human capital accumulation using future earnings as the collateral for a loan to pay the tuition fees), they end up either not investing in human capital or investing very little. Furthermore, if there are decreasing returns to the accumulation of human capital the final outcome does not maximize the size of the economic pie and therefore there may be scope for redistribution of resources from rich to poor individuals which, in turn, increases the size of the pie. This redistribution reallocate resources towards more profitable investments given that the returns to human capital accumulation are higher for those individuals (the relatively poor ones) who have less human capital. The theoretical idea has been extensively developed in the literature since the work by Galor and Zeira (1993) and Banerjee and Newman (1993). Further developments have been proposed by De Gregorio (1995) and Bénabou $(1996,2000)$. Empirical evidence has been found in favor of the hypothesis that inequality and credit constraints affect human capital by Flug et al. (1998), De Gregorio (1995) and Mejía (2003).

But the accumulation of human capital involves other complementary factors as well. This has been extensively documented in a number of recent empirical studies, some of which will be resumed in the next section. While some of these factors can be thought as being non-purchasable (neighborhood effects shaped by local communities, family background, socioeconomic characteristics, genes , provision of social connections, installation of preferences and aspirations in children), others are not (pre and post natal care, parent's level of education, distance to schools and different qualities of books, teachers and schools) ${ }^{2}$.

If the previously mentioned factors are important in determining differences in educational attainment across individuals, the distribution of this "socio-economic characteristics" across individuals matters. In other words, if the distribution of access to the schooling system is important, one should encounter differences in educational attainment across individuals, even in economies with complete coverage of public school provision. This does not rule out the importance of the lack of

\footnotetext{
${ }^{2}$ See Roemer (2000), Bénabou (2000) and Dardanoni et al. (2003), among others.
} 
financial resources to pay for the (monetary) costs of education ${ }^{3}$. As said before, different studies have already shown that they are in fact important. However, this paper emphasizes the effects of inequality of access to the schooling system on human capital accumulation decisions made by individuals. Also, the model addresses the equilibrium relation between inequality of opportunity and efficiency. More precisely, the model is used to study the relation between inequality of opportunities and efficiency, the latter measured by output per capita or per capita human capital.

The paper is organized as follows: the second section reviews the empirical evidence regarding the effects of some of the complementary factors mentioned above on educational outcomes. The third section presents the model and the fourth section the results of the simulation of the model using a (well behaved) distribution function to simulate different degrees of inequality of opportunity. The last section presents the main conclusions derived from the paper.

\section{Empirical evidence on the determinants of human capital}

Since the publication of the Coleman Report (Coleman et al., 1966) hundreds of papers have studied the relationship between school expenditure and the effects of complementary factors on different measures of educational outcomes in the United States. More precisely, The Coleman Report found that the socioeconomic composition of the student body had a significant effect on test scores after controlling for student background, school and teacher characteristics (Ginther et al., 2000). This findings attracted the attention of scholars and policymakers as one of its main conclusions was that schools characteristics were relatively unimportant in determining achievement, while family characteristics were found to be the main determinant of student success or failure (Hanushek, 1996). Since then, many studies have used different data sets and econometric specifications to improve the estimates of the effects of family background, parental education, neighborhood effects and many other socioeconomic characteristics on educational

\footnotetext{
${ }^{3}$ Family income has been found to have large explanatory power on longitudinal studies of educational outcomes accross individuals. However, family income or assets do not only affect the individual's capacity to pay for tuition costs but also many other factors such as the neighborhood where the kids grow up, their health, and the capacity to buy complementary factors to the educational process.
} 
outcomes $^{4}$. In a study with more than 5,000 undergraduates at UC San Diego Betts and Morell (1997) found that personal background (family income and race) and the demographic characteristics of former high school classmates, significantly affected the student's GPA. This result was obtained after controlling for the degree program in which the students were enrolled and the resources of the high school attended. Moreover, they found that school effects partially reflected the incidence of poverty and the level of education among adults in the school neighborhood. In a different paper Golghaber and Brewer (1997) found that family background characteristics had a significant effect on tests scores taken by 18,000 students in the 10th grade, even after controlling for school characteristics and the results on a previously taken math test by the same students. They found, for instance, that years of parental education and family income were positively related to test scores. Also, Blacks, Hispanic and kids coming from a family with no mother in the household had, on average, a lower predicted score in the math test. Another study by Groger (1997) found empirical evidence on the negative (and significant) effects of local violence on the likelihood of graduating from high school. While the average dropout rate in his sample is 21 percent, minor violence increases the dropout rate by 5 percentage points, moderate levels of violence raises it by 24 percent and substantial violence by 27 percent.

Data requirements in longitudinal studies to estimate the effects of school characteristics, family background and neighborhood effects on educational outcomes constitutes the main constraint to undertake research on the determinants of educational outcomes in developing countries. However, the use of randomized experiments to estimate the effects of changes in the complementary factors (such as: improving health conditions, provide educational inputs, and lower the costs associated with school attendance, among others) on different measures of educational outcomes has become one of the hottest topics in the development literature $^{5}$. The list of recent papers that evaluate the effects of improving the accessibility of these complementary factors is growing rapidly and a complete survey of their findings is not the purpose of this article. However, some examples are worth mentioning.

\footnotetext{
${ }^{4}$ For a reviw of the literature, as well as the main findings (and econometric specification problems) the reader is refered to Ginther et al. (2000) and Hanushek (1986 and 1996). The paper by Durlauf (2002) presents a complete review of how social interactions play an important role on the perpetuation of poverty, altough, not only through the human capital channel.

${ }^{5}$ The reader is refered to Duflo and Kremer (2003) and Kremer (2003) for a review of the methodology of randomized experiments as well as their main findings.
} 
One of this randomized experiments evaluates the effects of mass deworming in 75 school populations in Kenya. The results are very clear: "Health and school participation improved not only at program schools, but also at nearby schools, due to reduced disease transmission. Absenteeism in treatment schools was $25 \%$ (or 7 percentage points) lower than in comparison schools. Including this spillover effect, the program increased schooling by 0.15 years per person treated." (Kremer and Miguel, 2001). The same pattern of results were found in a similar randomized experiments in India (Bobonis et al., 2002, cited in Kremer, 2003).

In another randomized experiment conducted in Colombia, vouchers to cover more than half of the tuition costs of secondary education in private schools were distributed by lottery to kids in secondary school age from neighborhoods classified as falling in to the two lowest socioeconomic strata ${ }^{6}$. The effects of the program were estimated by Angrist et al. (2003) by measuring the differences in certain characteristics and test scores between voucher winners and a control group of nonparticipants in the program. After three years in the program, voucher winners were 15 percentage point more likely to have attended a private school, were $10 \%$ more likely to have completed the 8th grade and scored 0.2 standard deviations higher on standardized tests given to the whole population (voucher winners plus control group of nonparticipants in the program $)^{7}$.

From the empirical evidence presented above it is clear that the role played by complementary factors in the educational process is in fact important. In the following section we construct a model where the degree of inequality of access to the schooling system is a first order determinant of the levels of human capital and other economic variables.

\section{The basic structure of the model}

Consider a small economy operating under perfectly competitive markets. The production of the (single) final good is determined by a neoclassical production function that combines physical capital, human capital and unskilled labor.

\footnotetext{
${ }^{6}$ Neighborhoods in Colombia are stratified from 1 (the poorest) to 6 (the richest), mainly for purposes of setting utilities tariffs in a progressive manner.

${ }^{7}$ Other randomized experiments include: PROGRESA in Mexico (Schultz, forthcoming), School meals in Kenya (Kremer and Vermeersch, 2002), Provision of uniforms, textbooks and classroom construction in Kenya (Kremer et al., 2002), Provision of a second teacher (if possible, female) in one-teacher schools in India (Banerjee and Kremer, 2002).
} 
Individuals are identical regarding their preferences and abilities but may differ with regard to the cost they face of acquiring human capital because they have different access to the complementary factors of the educational process, just as explained in the previous section. In that sense, individuals face unequal opportunities of acquiring human capital. The distribution of this costs across individuals is assumed to be exogenously given. Given the costs of acquiring human capital, each individual decides how much time to devote to acquire human capital (if any), and then compares the income she would receive if she decides to work as a skilled worker with that one she would receive if she decides not to acquire human capital and work as an unskilled worker. In equilibrium, the aggregate level of human capital as well as the output level are determined by the distribution of the costs of acquiring human capital as well as on other parameters of the model.

Although unequal access to the complementary factors of the educational process can be partially linked to wealth or income inequality, there are some predetermined characteristics of individuals that cannot be modified and/or cannot be purchased in the market once the time to make investment decisions in education comes: pre and post-natal care, neighborhood effects, parental level of education, school quality, among others. In order to concentrate on the effects of inequality of opportunities on human capital investment decisions, it will be assumed that all individuals are endowed with the same share of the total capital stock of the economy and education is provided free.

\subsection{Production technology and firm's optimization conditions}

The technology of production of final goods combines unskilled labor, skilled labor (human capital) and physical capital according to a neoclassical production function characterized by aggregate constant returns to scale and diminishing marginal returns on each one of the factors of production (equation 3.1)

$$
Y=F\left(L^{u}, H, K\right)=\left(L^{u}\right)^{\alpha}(H)^{\beta} K^{1-\alpha-\beta}
$$

Where $L^{u}$ is the proportion of individuals who work as unskilled labor, $H$ is total human capital in the economy, determined by $H=L^{s} \bar{h}^{s}$, where $L^{s}$ is the proportion of individuals that acquire human capital and, $\bar{h}^{s}$ is the average level of human capital across those individuals that accumulate human capital and therefore work as skilled workers. $K$ is the aggregate capital stock. For the sake of simplicity it is assumed that the total population consists of a continuum of individuals of size 1 . Therefore $L^{u}+L^{s}=1$. 
Markets are perfectly competitive and firms choose the number of unskilled and skilled workers they hire as well as physical capital in order to maximize profits. The inverse demand for each one of the factors of production is given in equations 3.2 to 3.4 .

$$
\begin{gathered}
w^{u}=\alpha\left(L^{u}\right)^{\alpha-1}(H)^{\beta} K^{1-\alpha-\beta} \\
w^{s}=\beta\left(L^{u}\right)^{\alpha}(H)^{\beta-1} K^{1-\alpha-\beta} \\
r=(1-\alpha-\beta)\left(L^{u}\right)^{\alpha}(H)^{\beta} K^{-\alpha-\beta}
\end{gathered}
$$

Where $w^{u}$ is the unskilled wage rate, $w^{s}$ is the wage rate per unit of human capital (defined later on) and $r$ is the interest rate.

\subsection{Individual's human capital decision and occupational choice}

Individuals are identical in their preferences and abilities and each of them is endowed with one unit of time which they allocate between working and acquiring human capital (if any). However, individuals may differ in the costs they face per unit of human capital accumulated. As discussed in the introduction this assumption captures the idea that different individuals face different costs of acquiring human capital. Some individuals may be further from schools than others or may enjoy less efficient ways of transportation. Or, some individuals may not be well enough nourished and as a result may face higher costs of attending school. This assumption will be introduced in the model in a very simple way (probably the simplest one): for each unit of time that an individual allocates to the accumulation of human capital not only she sacrifices time to work but also has to pay an additional extra cost. The skills of an individual $i$, who devotes a fraction $u_{i}$ of her time to the accumulation of skills are determined by $b\left(u_{i}\right)$, and the total time she devotes to work is given by $\left(1-u_{i} \theta_{i}\right)$. Where $\theta_{i} \geq 1$, and $\theta_{i}-1 \geq 0$, reflects the additional cost of devoting a fraction $u_{i}$ of time to the accumulation of human capital. When $\theta_{i}=1$, the individual faces only the cost of time devoted to accumulate human capital and, when $\theta_{i}>1$, the individual faces two costs: the time devoted to acquire the skills, $u_{i}$, which is time that she sacrifices from work and an extra cost equal to $\left(\theta_{i}-1\right) u_{i}$. This last cost reflects the additional cost each individual faces of acquiring human capital. It can be thought of as the time that an individual with constraints $\left(\theta_{i}-1\right)$ has to work to pay the extra 
cost for the acquisition of skills $b\left(u_{i}\right)$. It is assumed that $\theta_{i}$ is distributed across individuals according to the distribution function $F(\theta)$. That is $\theta \sim F(\theta)^{8}$.

The total level of human capital devoted to work in the production of the final good by individual $i$ who faces an additional extra cost of acquiring human capital $\left(\theta_{i}-1\right)$ is given in equation 3.5.

$$
h_{i}=\left(1-u_{i} \theta_{i}\right) b\left(u_{i}\right)
$$

It is assumed that $b^{\prime}(u)>0$ and $b^{\prime \prime}(u)<0$. In words, there are positive and decreasing marginal returns to time investment in human capital formation.

In order to simplify the analysis, assume the form $b\left(u_{i}\right)=u_{i}^{\gamma}$, with $\gamma<1$, which satisfies the previous conditions.

Each individual in the economy chooses $u_{i}$ in order to maximize her total income, taking the wage rate of skilled labor as given. Each individual solves the following problem:

$$
\begin{gathered}
\max _{u_{i}} w^{s} h_{i}=\max _{u_{i}} w^{s}\left(1-u_{i} \theta_{i}\right) u_{i}^{\gamma} \\
\text { subject to: } u_{i} \theta_{i}<1
\end{gathered}
$$

The optimal amount of time individual $i$ invests in the acquisition of human capital is given in equation $3.7^{9}$.

$$
u_{i}^{*}=\frac{\gamma}{\theta_{i}(1+\gamma)}
$$

Not surprisingly, the higher it is the additional cost of acquiring human capital faced by individual $i$, the lower it is the time she invests in the acquisition of $\mathrm{it}^{10}$.

Given the extra cost each individual faces of acquiring human capital and the optimal amount of time investment in human capital accumulation, she compares the income she would receive under the two alternative occupations: If she decides to become an unskilled worker, she would devote all her time to work and she would receive an income equal to the wage of an unskilled worker. That is:

\footnotetext{
${ }^{8}$ In other words, each individual in the economy is 'endowed' with a value of $\theta_{i}$ which determines the cost she faces per unit of time she devotes to the accumulation of human capital.

${ }^{9}$ Note that $u_{i} \theta_{i}=\frac{\gamma}{1+\gamma}<1$.

${ }^{10}$ Note that from the optimization conditions an econometric especifications can be derived if the resercher has some hypothesis about the factors that determine $\theta_{i}$ (see the Appendix (A1) for an example).
} 


$$
\text { Income of an unskilled worker }=w^{u}
$$

In the other hand, if she decides to be a skilled worker, she would optimally invest a fraction $u_{i}^{*}$ of her time in the formation of human capital and then, her total income would be given by equation 3.9, which is obtained from replacing equation 3.7 in the objective function in 3.6.

$$
\text { Income of a skilled worker }=w^{s} \frac{\gamma^{\gamma}}{(1+\gamma)^{1+\gamma}}\left(\frac{1}{\theta_{i}}\right)^{\gamma}
$$

Each individual in the economy decides whether to work as a skilled or unskilled worker by comparing the income she would get under the two alternative occupations (equations 3.8 and 3.9) ${ }^{11}$. More precisely, each individual $i$ in the economy takes the wage rates $w^{u}$ and $w^{s}$ as given and, depending on the extra cost of acquiring human capital that she faces, makes an occupational choice. Comparing equations 3.8 and 3.9 there exists a threshold value of the extra cost of acquiring human capital given by equation 3.10 that determines whether each individual decides to invest in human capital and work as a skilled worker or, work as an unskilled worker.

$$
\theta^{*}=\left(\frac{w^{s}}{w^{u}}\right)^{\frac{1}{\gamma}}\left(\frac{\gamma^{\gamma}}{(1+\gamma)^{1+\gamma}}\right)^{\frac{1}{\gamma}}
$$

Individuals who face a cost higher than the threshold cost $\theta^{*}$ will decide not to acquire any human capital, whereas those individuals who face a lower cost than the threshold value will devote a fraction $u_{i}^{*}$ (equation 3.7) of their time to the acquisition of human capital and will work as skilled workers. The optimal occupational decision by individual $i$ is summarized in equations 3.11 and 3.12 .

$$
\text { If } \theta_{i}>\theta^{*} \Rightarrow \text { Work as unskilled worker and receive income }=w^{u}
$$

$$
\text { If } \theta_{i} \leq \theta^{*} \Rightarrow \text { Invest } u_{i}^{*} \text { in the acquisition of human capital, }
$$

\footnotetext{
${ }^{11}$ This setup is equivalent to one where each individual maximizes a monotonic utility function that depends only on the consumption of the final good.
} 
work as skilled worker and receive income $=w^{s} \frac{\gamma^{\gamma}}{(1+\gamma)^{1+\gamma}}\left(\frac{1}{\theta_{i}}\right)^{\gamma}$

\subsection{Human Capital}

The average level of human capital devoted to the production of the final good among those individuals who decide to work as skilled workers is given in equation 3.13 .

$$
\bar{h}^{s}=\frac{\frac{\gamma^{\gamma}}{(1+\gamma)^{1+\gamma}} \int_{1}^{\theta^{*}}\left(\frac{1}{\theta}\right)^{\gamma} d F(\theta)}{F\left(\theta^{*}\right)}
$$

Given that individuals who decide to work as unskilled workers do not invest any time in the formation of human capital, the total level of human capital in the economy is given by the proportion of individuals who work as skilled workers (i.e. those who devote a positive amount of time to the acquisition of human capital) times the average level of human capital among this group of individuals (equation 3.13). Given the assumption that the total size of the population is 1, the total human capital in the population is equal to the average human capital across all individuals and is given in equation 3.14.

$$
L^{s} \bar{h}^{s}=H=\frac{\gamma^{\gamma}}{(1+\gamma)^{1+\gamma}} \int_{1}^{\theta^{*}}\left(\frac{1}{\theta}\right)^{\gamma} d F(\theta)
$$

Where $F\left(\theta^{*}\right)$ is the proportion of individuals who decide to invest a positive fraction of their time in the formation of human capital.

\subsection{Labor market equilibrium}

To determine the labor market equilibrium quantities and prices we need to determine the threshold level of the cost of acquiring human capital, $\theta^{*}$. From equations 3.2 and 3.3, the ratio of skilled to unskilled wakes is given in equation 3.15.

$$
\frac{w^{s}}{w^{u}}=\frac{\beta}{\alpha} \frac{L^{u}}{H}=\frac{\beta}{\alpha} \frac{L^{u}}{L^{s} \bar{h}^{s}}
$$


From equations 3.11 and 3.12 we know that the proportion of individuals who decide to work as unskilled workers is equal to $1-F\left(\theta^{*}\right)$, whereas the proportion who decide to be skilled workers is given by $F\left(\theta^{*}\right)$. Replacing these two results and using equation 3.13 to replace for the average level of human capital across skilled individuals, the ratio of skilled to unskilled wages is given in equation 3.16.

$$
\frac{w^{s}}{w^{u}}=\frac{\beta}{\alpha} \frac{\left(1-F\left(\theta^{*}\right)\right)}{\frac{\gamma^{\gamma}}{(1+\gamma)^{1+\gamma}} \int_{1}^{\theta^{*}}\left(\frac{1}{\theta}\right)^{\gamma} d F(\theta)}
$$

Equations 3.10 and 3.16 determine the labor market equilibrium. More precisely, replacing the ratio of skilled to unskilled wages from equation 3.16 in equation 3.10 and after doing some algebra, the threshold value of the cost of acquiring human capital is determined in equation 3.17.

$$
\theta^{*}=\left[\frac{\beta}{\alpha} \frac{1-F\left(\theta^{*}\right)}{\int_{1}^{\theta^{*}}\left(\frac{1}{\theta}\right)^{\gamma} d F(\theta)}\right]^{\frac{1}{\gamma}}
$$

Appendix A2 provides a proof for the existence and uniqueness of the labor market equilibrium described in equation 3.17 .

\subsection{Human capital distribution}

As discussed before, those individuals who face a higher cost of acquiring human capital than the threshold cost, that is, $\theta_{i}>\theta^{*}$, will not devote any time to the acquisition of education and therefore will not acquire any human capital. The proportion of these individuals out of the total population, as was shown before is $1-F\left(\theta^{*}\right)$. The remaining individuals will devote a positive amount of time to acquire education and therefore will have a positive amount of human capital, given by: $\frac{\gamma^{\gamma}}{(1+\gamma)^{1+\gamma}}\left(\frac{1}{\theta_{i}}\right)^{\gamma}$. The amount of human capital of agent $i$ is inversely related to the cost she faces of acquiring human capital. With this information we can construct an approximate indicator of human capital inequality, that is, an approximate Gini coefficient. Figure 3.1, depicts the human capital Lorenz curve implied by the model. Individuals are ordered in the x-axis according to the costs they face of acquiring human capital from highest (at the origin) to the lowest (1) on the right. Recall that the size of the total population is being normalized to 
one. A proportion $1-F\left(\theta^{*}\right)$ of individuals do not acquire any human capital and therefore the Lorenz curve is truncated up to the individual with $\theta_{i}=\theta^{*}$. From that point on, individuals devote a positive amount of their time to education and start to have positive amounts of human capital. In figure 3.1, after the individual with $\theta_{i}=\theta^{*}$, the cumulative human capital is greater than zero, (and decreasing in $\theta_{i}$, and therefore increasing as we move to the right of the graph $)^{12}$. The human capital Gini coefficient is defined as the area between the $45^{\circ}$ line and the Lorenz curve. From figure 3.1 the human capital Gini is defined as:

$$
\operatorname{Gini}_{h}=\frac{A+B}{A+B+C}
$$

If human capital were equally distributed across individuals, this area would be zero and so would be the Gini coefficient. However, as human capital is less equally distributed the area becomes larger and so does the human capital Gini coefficient.

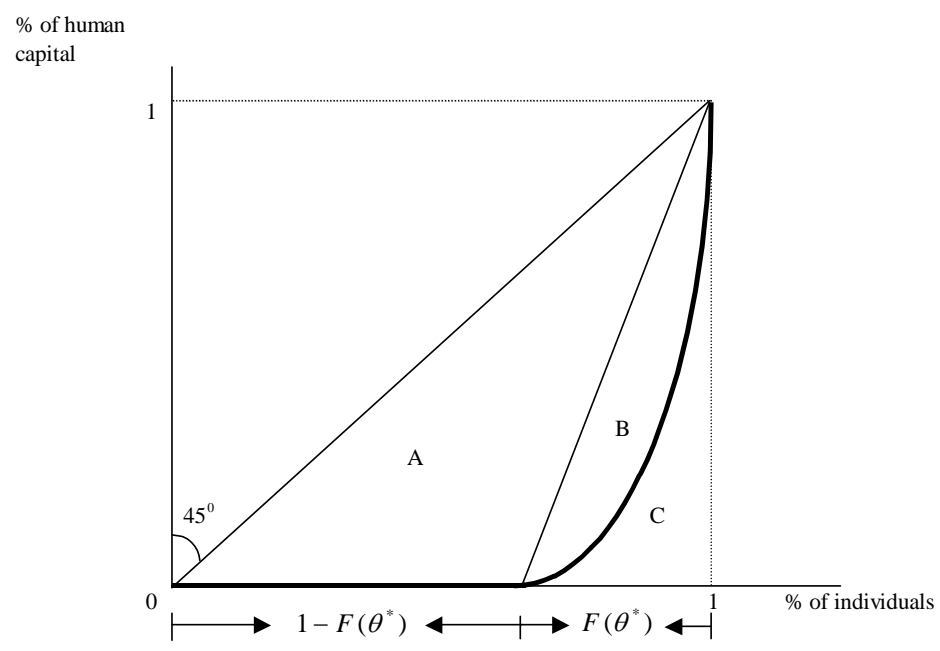

Figure 3.1:

Although the Lorenz curve is non-linear after some threshold value, let us

\footnotetext{
${ }^{12}$ Figure 5.1 in Appendix (b) presents the Education Lorenz curves for two countries (Korea and India) in two points in time (1960 and 1990) for each country. Note that the pattern of the Lorenz curves predicted in the model (the fact that they are truncated) is observed in the actual data. The reader is refered to Thomas et al. (2000) for details.
} 
define the approximate Gini coefficient as $G I \tilde{N} I_{h}=\frac{A}{A+B+C}$. This biases the Gini downwards but greatly simplifies the analysis. By calculating the area of the triangles from the last formula, it can be shown that the approximate human capital Gini coefficient positively depends on the proportion of individuals who decide not to acquire any human capital. More precisely, the approximate human capital Gini coefficient is given by equation 3.19.

$$
\tilde{G I N} I_{h}=\frac{1}{4}\left(1-F\left(\theta^{*}\right)\right)
$$

The higher is the proportion of agents who face a cost of acquiring human capital higher than the threshold value $\theta^{*}$, the higher is the human capital Gini coefficient. In other words the measure of human capital inequality directly depends on the number of individuals who decide not to accumulate human capital. Although this is only an approximation, it seems to be supported by the empirical evidence presented in Thomas et al. (2000). More precisely, the authors find a strong negative relation between average years of educational attainment and the human capital Gini Index (see Figure 5.2 in Appendix (A3) taken from Thomas et al. (2000)).

\subsection{Income (wage) distribution}

As explained before, agents are assumed to differ only with regard to the costs of acquiring human capital. Although this is a strong assumption, it is valid if one wants to concentrate on the effects of inequality of opportunities on human capital accumulation. A more complete model would have to assume also heterogeneity of wealth as well as heterogeneity of opportunities across individuals. For the moment we will assume that all agents are endowed with the same share of the aggregate capital stock and as a result income heterogeneity arises from heterogeneity in human capital and the occupational choice agents make.

Wage income of agent $i$ in the economy is determined in the following way:

If $\theta_{i}>\theta^{*}$, agent $i$ works as an unskilled worker and gets wage income equal to $w^{u}$

If $\theta_{i} \leq \theta^{*}$, agent $i$ invests $u_{i}^{*}$ of her time acquiring human capital and ed(3n81) wage income equal to $w^{s} \frac{\gamma^{\gamma}}{(1+\gamma)^{1+\gamma}}\left(\frac{1}{\theta_{i}}\right)^{\gamma}$ 
As an example, imagine that the number of agents whose cost of acquiring human capital is lower than the threshold value is relatively large, given a certain value of the threshold, $\theta^{*}$. That is, $1-F\left(\theta^{*}\right)$ is large, given $\theta^{*}$. The Lorenz curve associated with this example will take the form of figure 3.2. Quite a large fraction of the population $1-F\left(\theta^{*}\right)$ receives a less than proportional fraction of the total wage payments, while a relatively small fraction, $F\left(\theta^{*}\right)$, ranked by the inverse of their value of $\theta_{i}$, receive an increasing proportion of all wage payments.

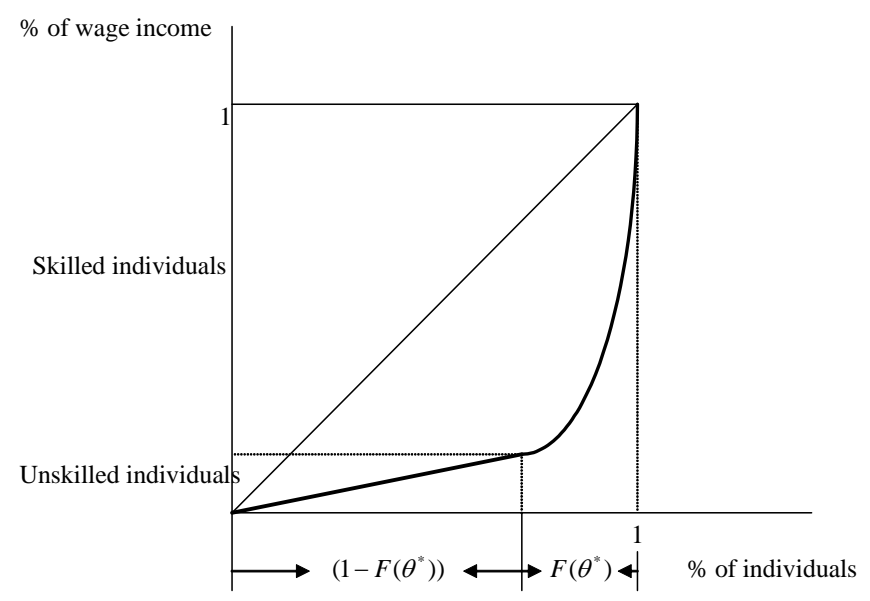

Figure 3.2:

\section{Numerical simulation}

In this section we present the main results of the simulation of the model. More precisely, we specify a (well behaved) distribution function for the cost of acquiring human capital (which is the only exogenous part of the model presented in the last section) and then implement a mean-preserving spread to the distribution ${ }^{13}$.

\footnotetext{
${ }^{13}$ Altough this is a strong restriction in the kind of changes in the distribution that we allow, it isolates changes in the dispersion of the distribution from changes in the mean. An interesting but different exersise is to allow for other changes in the distribution that do not necessarily preserve the mean. We leave this for further work.
} 
The results of the simulation will tell how the endogenous variables of the model respond to changes in the distribution of costs of acquiring human capital across individuals while keeping the mean of the distribution unchanged.

The following analysis describes the main characteristics of the distribution used in the simulation as well as the main findings. We are particularly interested in the results regarding the relation between human capital, skilled to unskilled wages ratio, inequality measures and total output. As will become apparent soon, the relation between efficiency (total and per capita output and human capital) and inequality of income and opportunities derived from the simulation is negative.

Let the cumulative distribution function of the costs of acquiring human capital be that specified in equation 4.1. That is, let $\theta_{i} \sim F(\theta)$, where:

$$
F(\theta)=\left\{\begin{array}{lll}
0 & \text { for } & \theta<1 \\
{\left[\frac{\phi}{1+\phi}\right]^{\phi}(\theta-1)^{\phi}} & \text { for } & \theta \in\left[1,1+\frac{1+\phi}{\phi}\right] \\
1 & \text { for } & \theta>1+\frac{1+\phi}{\phi}
\end{array}\right.
$$

Where $\phi \in[1, \infty)$

Note that some of the characteristics of $F(\theta)$ are:

i. Mean: $E(\theta)=\bar{\theta}=2 \quad \forall \phi$

ii. Median: $F\left(\theta_{m}\right)=\frac{1}{2} \Rightarrow \theta_{m}=\frac{1+\phi}{\phi 2^{1 / \phi}}+1$

iii. As $\phi \rightarrow 1$, the distribution function in equation 4.1 approaches the Uniform distribution.

Define: $\Omega=\frac{\text { median }}{\text { mean }}$. That is: $\Omega=\frac{1+\phi}{\phi 2^{\frac{1}{\phi}+1}}+\frac{1}{2}$.

Given that the mean of the distribution specified in equation 4.1 is constant for all values of the parameter $\phi$, any change in this parameter modifies the shape (dispersion) of the distribution while leaving the mean unchanged.

The parameter $\Omega$ is a measure of inequality for values of $\phi$ such that $\phi \in$ $[1,2.25]^{14}$. We will use this fact to carry out the simulation. In particular, higher

\footnotetext{
${ }^{14}$ The details are available from the authors upon request.
} 
values of $\phi$ are associated with a more unequal distribution of the costs of education across individuals.

After fixing some parameter values ${ }^{15}$, the main point of the simulation is that of finding the value of $\theta^{*}$ from equation 3.17 using equation 4.1. In words, this is equivalent to finding the value $\theta^{*}$ such that the labor market is in equilibrium. Recall also that the individual with $\theta_{i}=\theta^{*}$ is indifferent between investing a fraction $u_{i}^{*}$ of time in the formation of human capital (equation 3.7) and working as a skilled worker and, working as an unskilled worker. Having found the value of $\theta^{*}$, and using the form of the distribution from equation 4.1 we can obtain all the endogenous variables of the model from the main equations derived in the last section.

The next step is to modify the shape of the distribution by changing the parameter $\phi$. Then, for each value of $\phi \in[1,2.25]$ we obtain the value of $\theta^{*}(\phi)$ (such that the labor market is in equilibrium) and all endogenous variables in the model.

The main results are presented in the panels of Figure $4.1^{16}$. From the top left panel (a) it is clear that a higher value of the parameter $\Omega$ is associated with lower level of total (and per capita) human capital. In words, a more unequal distribution of opportunities (costs of acquiring human capital) is associated with a lower level of average human capital across all individuals. From the top right panel (b) the relation between human capital and wage inequality is negative. That is, higher levels of human capital are associated with a more equal distribution of wage income. The last two panels show the relation between output and two different measures of inequality. In lower left panel (c) the relation between output and our measure of inequality of opportunities is negative. That is, a higher level of inequality of opportunities is associated with a lower level of total (and average) output. The relation between output and income (wage) inequality is shown in the lower right panel (d). Higher levels of wage inequality are associated with a lower level of output.

\footnotetext{
${ }^{15}$ We use the following parameter values: $\alpha=0.3, \beta=0.3, K=1$ and $\gamma=0.7$.

${ }^{16}$ The different curves presented in Figure 4.1 are not 'smooth' because the simulation of the model involves numerical approximations of integrals and of the solutions to non-linear equations.
} 

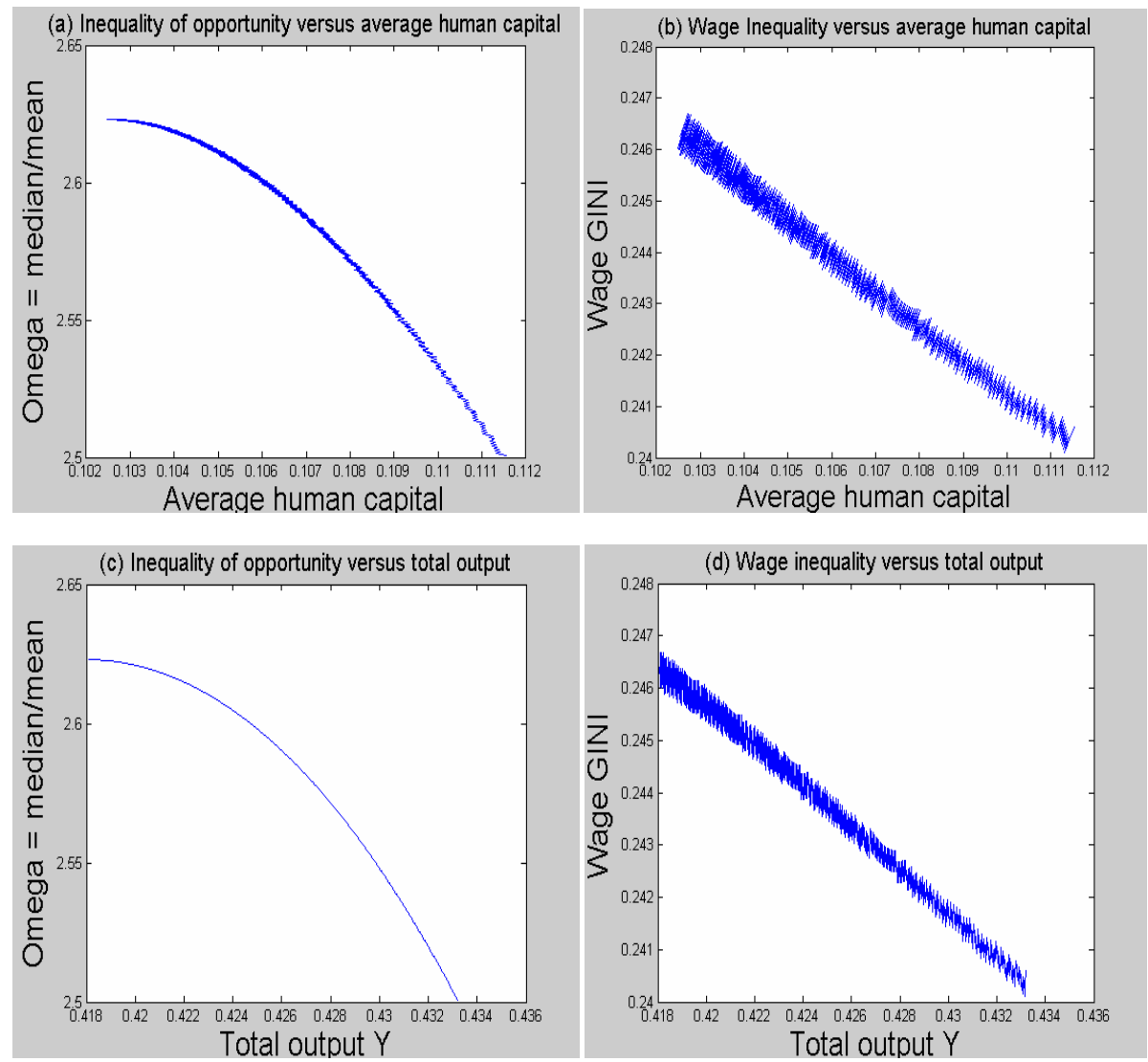

Figure 4.1: 


\section{Conclusions}

The paper develops an heterogeneous agent general equilibrium model with unequal opportunities of access to the educational system. More precisely, we specify inequality of opportunities among individuals as a differential cost of access to the educational process. In equilibrium, the endogenous variables of the model are determined by the form of the distribution of costs across individuals as well as the parameters of the technologies of production of the final good and human capital formation. In order to study the relation between the endogenous variables of the model we do a numerical simulation of the model using a well behaved (for our main purposes) distribution function of the costs of acquiring human capital. More precisely, we find a negative relation between inequality of opportunities and income and two different measures of efficiency (output per capita and human capital per capita). An additional exercise (not presented in this version of the paper) uses a different distribution function and the main results regarding the trade-off between efficiency and equality are maintained ${ }^{17}$. Although the distribution used in the paper for the simulation is very particular, it is a tractable one in the sense that it allows to isolate changes in the shape (dispersion) of the distribution from changes in the mean. We are aware that this distribution is one of the many possible distributions that we can observe in reality. Further work will focus on the identification of the sufficient and necessary conditions on the distribution function for the trade-off between equality of opportunity and efficiency in the formation of human capital to exist.

\footnotetext{
${ }^{17}$ These results are available from the authors upon request.
} 


\section{References}

Angrist, J., Bettinger, E., Bloom, E., Kling, E., and M. Kremer, 2003, "Vouchers for Private Schooling in Colombia: Evidence from a Randomized Natural Experiment", American Economic Review, 92(5), December.

Bénabou, R., 1996, "Equity and Efficiency in Human Capital Investment: The Local Connection", Review of Economic Studies, 62, 237-264.

Bénabou, R., 2000, "Meritocracy, Redistribution, and the Size of the Pie", in Arrow et al. Meritocracy and Economic Inequality, Princeton University Press.

Banerjee, A.V. and A.F. Newman, 1993, "Occupational Choice and the Process of Development", Journal of Political Economy, 101(2): 274-298.

Betts, J. and D. Morell, 1999, "The Determinants of Undergraduates Grade Point Average: The relative Importance of Family Background, High School Resources, and Peer group Effects", Journal of Human Resources, 34, 2, 268-293.

Dardanoni, V., G. Fields, P. Roemer and M. Sanchez, 2003, "How demanding should equality of opportunity be, and how much have we achieved", unpublished manuscript.

De Gregorio, J., 1996, "Borrowing constraints, human capital accumulation, and growth", Journal of Monetary Economics 37, 49-71.

Duflo, E. and M. Kremer, 2003, "Use of Randomization in the Evaluation of Development Effectiveness", mimeo, MIT.

Durlauf, S., 1996, "Neighborhood Feedbacks, Endogenous Stratification, and Income Inequality", in: Barnett, Gandolfo, and Hillinger eds., Dynamic Disequilibrium Modelling, Cambridge, Cambridge university Press.

Durlauf, S., 2002, "Groups, Social Influences and Inequality: A Membership Theory Perspective on Poverty Traps", University of Wisconsin..

Fernandez, R. and Rogerson, 1996, "Keeping People Out: Income Distribution, Zoning, and the Quality of Public Education", Quarterly Journal of Economics, 38, 1, 25-42.

Flug, K, A. Spilimbergo and E. Wachteinheim, 1998, "Investment in education: do economic volatility and credit constraints matter?" Journal of Development Economics 55, 465-481.

Galor, O. and J. Zeira, 1993, "Income Distribution and Macroeconomics", Review of Economic Studies, 60: 35-52. 
Galor, O. and D. Tsiddon, 1997, "Technological Progress, Mobility, and Economic Growth", American Economic Review, Vol. 87, No. 3, 363-382.

Ginther, D., R. Haveman and B. Wolfe, 2000, "Neighborhood Attributes as Determinants of Children's Outcomes: How Robust are the Relationships", Journal of Human Resources, Vol. 35, No. 4, 603-642.

Goldhaber, D. and D. Brewer, 1997, "Why don't Schools and Teachers Seem to Matter? assessing the Impacts of Unobservables on Educational Productivity", Journal of Human Resources, 32, 3, 505-523.

Grogger, G., 1997, "Local Violence and Educational Attainment", Journal of Human Resources, 32, 4, 659-682.

Hanushek, E., 1986, "The Economics of Schooling: Production and Efficiency in Public Schools", Journal of Economic Literature, vol. 24, No. 3, 1141-1177.

Hanushek, E., 1996, "Measuring Investment in Education", Journal of Economic Perspectives, Vol. 10, No. 4, 9-30.

Kremer, M., 2003, "Randomized Evaluation of Educational Programs in developing Countries: Some Lessons, forthcoming in American Economic Review papers and proceedings..

Roemer, J., 2000, "Equality of Opportunity", in Arrow et al. Meritocracy and Economic Inequality, Princeton University Press.

Schultz, T. Paul, "School Subsidies for the Poor: Evaluating the Mexican Progresa Poverty Program", Journal of Development Economics, forthcoming.

Thomas, V., Y. Wang and X. Fan, 2000, "Measuring Education Inequality: Gini Coefficients of Education", World Bank. 


\section{Appendix}

\section{(A1)}

Note that from equation $3.7, b\left(u_{i}^{*}\right)=\left(\frac{\gamma}{\theta_{i}(1+\gamma)}\right)^{\gamma}$ denotes the level of human capital at the optimum for individual $i$. Recall that $\theta_{i}$ is different for all individuals and determines the extra cost of acquiring human capital based on socioeconomic characteristics. Let, only as an example, these set of costs be determined by a weighted average ${ }^{18}$ of two characteristics: the inverse of parent's level of education $\left(\varepsilon_{i}\right)$ and an inverse measure of health $\left(\varkappa_{i}\right)$. That is: $\theta_{i}=\delta \varepsilon_{i}^{\lambda} \varkappa_{i}^{1-\lambda}$, with $\lambda$ unknown. If parents level of education and health characteristics are observed for each individual and we are able to proxy $b\left(u_{i}^{*}\right)$ with test scores or an indicator of years of schooling for each individual $\left(s_{i}\right)$ then, the effects of parents education and health can be estimated from the log-linearization of the optimal amount of human capital derived above. That is:

$$
\ln s_{i}=\gamma \ln \frac{\gamma}{\delta(1+\gamma)}-\gamma \lambda \ln \varepsilon_{i}-\gamma(1-\lambda) \ln \varkappa_{i}
$$

From the estimation of the above equation, a researcher can estimate the effects of different characteristics of the individual on observed educational outcomes. In many of the empirical studies reviewed in the introduction this is the form that is estimated.

\footnotetext{
${ }^{18}$ It is not necessary that the weights add up to 1 , but is a hypothesis that can be tested.
} 


\section{(A2)}

Existence of the equilibrium in the labor market

There exists a unique equilibrium solution under a fairly general context. The market solution exists if there is a cost threshold $\theta^{*}$ which solves the following non linear equation in $\theta$ for any given set of parameters $\gamma, \alpha, \beta \in(0,1)$ :

$$
k\left(\theta^{*}, \gamma\right)-g\left(\theta^{*}, \gamma, \alpha, \beta\right)=0
$$

where $k(\theta, \gamma)=\theta^{\gamma} \int_{1}^{\theta^{*}} y^{-\gamma} f(y)$ and $g(\theta, \gamma, \alpha, \beta)=\frac{\beta}{\alpha}(1-F(\theta))$ and $f($.$) is the$ cost density function.

First, note that $k($.$) is non decreasing in \theta$ and that $g($.$) is non-increasing in$ $\theta$. Thus, $k()-.g($.$) is non decreasing in \theta$. If $f($.$) is integrable then k()-.g($.$) is$ continuous and the image of the support of $\theta([1, S])$ is a compact and a connected subset of the real numbers. That is, the image is a bounded and closed interval which we denote by $I=[a, b]$. Since $f()-.g($.$) is non decreasing, a=f(1, \gamma)-$ $g(1, \gamma, \alpha, \beta)=-\frac{\beta}{\alpha}<0$ and $b=f(S, \gamma)-g(S, \gamma, \alpha, \beta)=S^{\gamma} \int_{1}^{S} y^{-\gamma} d F(y)>0$. Therefore, $0 \in I$, that is, there exists $\theta^{*} \in(1, S)$ for which $f\left(\theta^{*}, \gamma\right)-g\left(\theta^{*}, \gamma, \alpha, \beta\right)=$ 0. Q.E.D.

Remark 1: The only assumption we need for the proof is that $f($.$) is Riemann$ integrable. Continuous or piecewise continuous density functions are particular cases of Riemann integrable functions.

Remark 2(uniqueness) : Note that the function $k($.$) is not strictly increasing$ only in a particular case where $\int_{1}^{\theta^{*}} y^{-\gamma} f(y)=0$. If we assume, furthermore, that the density is strictly positive on some interval $[0, \epsilon]$ in the support of $\theta$ then $k()-.g($.$) is strictly increasing on the whole support of \theta$ and is, therefore, injective, meaning that there is a unique equilibrium solution. If that condition is not satisfied then no solution can be in the range $[1, \epsilon]$ anyway since $f(x, \gamma)-$ $g(x, \gamma, \alpha, \beta)=-\frac{\beta}{\alpha}<0 \forall x \in[1, \epsilon]$. Therefore, the equilibrium solution must lie in the complement interval $(\epsilon, S]$ on which the function $k()-.g($.$) is now strictly$ increasing.

Thus, there exist a unique solution to the market equilibrium whenever $f($.$) is$ integrable. 
(A3)
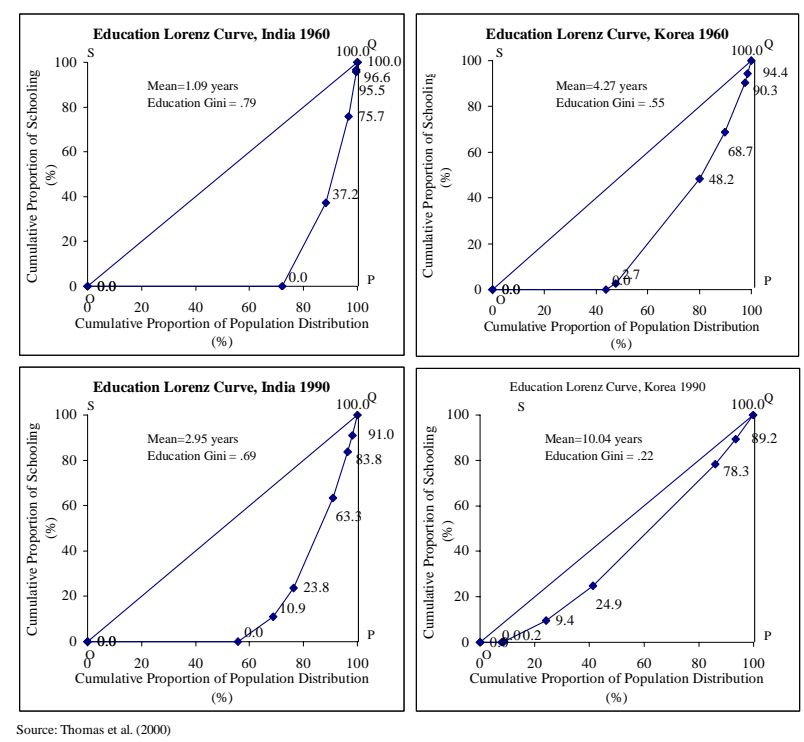

Figure 5.1: 


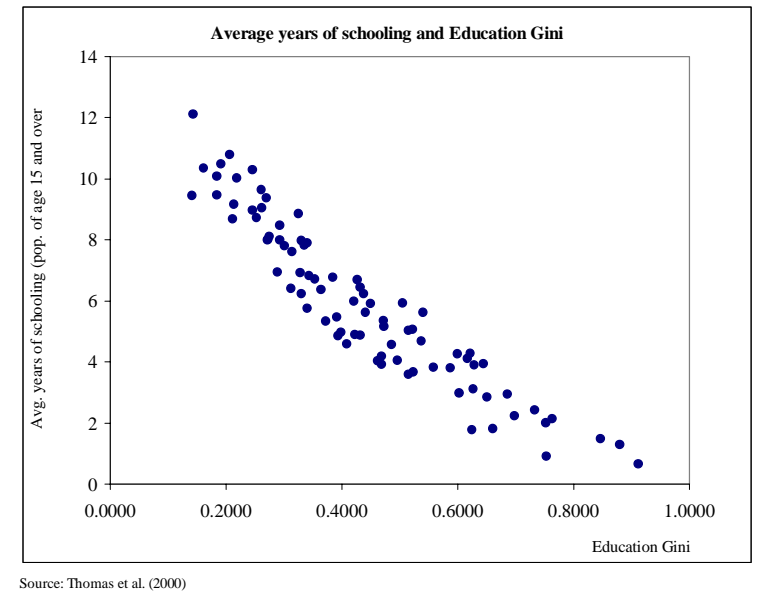

Figure 5.2: 